\title{
Total and Effective Coronary Blood Flow in Coronary and Noncoronary Heart Disease
}

\author{
David Mymin and Gyan P. Sharma \\ From the Cardiology and Cardio-Pulmonary Divisions, Departments of Medicine \\ and Surgery, University of Manitoba and St. Boniface General Hospital, \\ Winnipeg, Canada
}

A B S T RACT There are no data available concerning total coronary blood flow to the whole heart (CBF) in man. "Effective" or "nutrient" coronary blood flow to the whole heart (MBF), supposedly a measure of flow through exchanging channels of the coronary circulation, has been measured but its validity has not been established. Accordingly, $\mathrm{CBF}$ and $\mathrm{MBF}$ were measured in 9 normal subjects, 26 patients with coronary heart disease ( $\mathrm{CHD}$ ), and 19 with noncoronary, mostly valvular heart disease (NCHD), by coincidence counting ${ }^{84} \mathrm{Rb}$ technique. Two methods were used: single bolus ( 24 cases) and continuous infusion (30 cases). Various other parameters including myocardial oxygen utilization $\left(\mathrm{MVO}_{2}\right)$ and lactate extraction ratio were determined.

In the normal subjects $\mathrm{CBF}(386 \pm 77 \mathrm{ml} / \mathrm{min})$ was significantly higher $(P<0.05)$ than in CHD $(288 \pm 124$ $\mathrm{ml} / \mathrm{min})$ and NCHD $(292 \pm 111 \mathrm{ml} / \mathrm{min})$. Likewise the normal MBF $(380 \pm 81 \mathrm{ml} / \mathrm{min})$ was significantly higher $(P<0.01)$ than in $\mathrm{CHD}(251 \pm 105 \mathrm{ml} / \mathrm{min})$ as well as NCHD (258 $\pm 104 \mathrm{ml} / \mathrm{min})$. The myocardial $\mathrm{Rb}$ extraction ratio $\left({ }^{\mathrm{E}} \mathrm{Rb}\right)$ was significantly lower in normal subjects $(39 \pm 9 \%)$ than in CHD $(50 \pm 7 \%)$ and NCHD $(52 \pm 11 \%)$ and this supports the view that ${ }^{\mathrm{E}} \mathrm{Rb}$ is flowdependent.

In both $\mathrm{CHD}$ and NCHD there was significant diminution of $\mathrm{MVO}_{2}$ as well as $\mathrm{CBF}$. In $\mathrm{CHD}$ this was accompanied by a significant anaerobic trend but in NCHD it was not. It might therefore appear that in $\mathrm{CHD}$, $\mathrm{MVO}_{2}$ is determined by perfusion whereas in NCHD, perfusion is determined by $\mathrm{MVO}_{2}$. In comparing $\mathrm{CBF}$ with $\mathrm{MBF}$ by paired observation testing, there was no significant difference in the normals $(P>0.3)$, whereas the differences were significant in $\mathrm{CHD}(P<0.01)$ and NCHD $(P<0.02)$. This was merely a reflection of

Reccived for publication 3 April 1973 and in revised form 24 September 1973. a reduced ratio of myocardial to total body ${ }^{\mathrm{E}} \mathrm{Rb}$ in $\mathrm{CHD}$ and $\mathrm{NCHD}$, and available evidence indicates that this may be an expression of depressed transport of $\mathrm{Rb}^{+}$ rather than true shunting.

\section{INTRODUCTION}

Many methods have been put forward for the measurement of coronary blood flow in man but none can be considered entirely satisfactory.

Wide use has been made of techniques based on indicator substances which diffuse passively into the myocardial cell. They provide flow data which must be expressed per unit of heart muscle (unit flow) and yet cannot be accepted as true average or mean values in all circumstances. The nitrous oxide technique (1), depending on coronary sinus sampling, purports to measure blood flow per unit of heart muscle drained by this system. However, in a heterogeneously perfused organ reduced flow to certain zones may well prolong the time required for myocardial equilibration beyond the usual 10 min period of $\mathrm{N}_{2} \mathrm{O}$ breathing. Furthermore, because of the relatively high solubility of $\mathrm{N}_{2} \mathrm{O}$ in blood, even a stable arterial concentration cannot be attained within this period. Prolonged small differences in arteriovenous gas concentration become highly significant in this situation and because of this, especially sensitive techniques of measurement (which are beyond the scope of the traditional nitrous oxide method) are required (2-4). Thus, in the presence of coronary disease this method has tended to overestimate average flow.

Washout techniques using bolus injection of ${ }^{133} \mathrm{Xe}(5)$ or ${ }^{85} \mathrm{Kr}$ (6) require isolation of the coronary circulation either by selective arterial injection of indicator or coronary venous sampling, and thus can claim only to measure flow per unit of heart muscle perfused by, or drained by the vessel in question. The same disadvantage, that 
of inhomogeneity of flow both topographically and between layers, as occurs particularly in coronary disease, limits their reliability. The adequacy of delivery of the tracer to areas of below average flow is questionable. The unit flow value is not a valid average but an overestimate since the isotope clearance curve is dominated by well perfused areas. These and other difficulties inherent in the various inert gas techniques have been discussed by several authors $(2-4,7-9)$.

Indicator dilution methods have been used for the measurement of coronary sinus flow (10-12). These have the advantage of measuring absolute rather than unit flow, but nevertheless, only a fraction of the entire coronary flow is involved. If one accepts the normal values for man which have been published to date then coronary sinus flow (12) is not greater than approximately $50 \%$ of myocardial blood flow (13-15).

By the use of substances that are actively transported into the myocardial cell, it is possible to measure whole heart blood flow. ${ }^{84} \mathrm{Rb}$ is particularly useful in this respect since it is a positron emitter and its activity can therefore be measured by coincidence counting. This is an extremely effective method of field isolation (16) and with the use of a double coincidence counting technique the whole heart can be "separated" from its surroundings. Since the entire organ uptake of isotope is measured, all zones are represented according to their degree of perfusion. Bing et al. have developed this technique for measurement of "nutrient" or "effective" myocardial blood flow $(\mathrm{MBF})^{1}(17)$ and values for normal subjects and patients with coronary disease have been reported by them and by other investigators $(13-15,18)$.

The relation of nutrient flow, which is supposedly a measure of flow through exchanging channels of the coronary circulation, to coronary blood flow ( $\mathrm{CBF}$ ), defined as the entire flow through all channels of the coronary circulation (exchanging or otherwise) is unknown. The very term nutrient flow is of uncertain validity. Its measurement by the technique of Bing et al. (17), based on Sapirstein's hypothesis (19) assumes that the uptake of $\mathrm{Rb}^{+}$by an organ is directly proportional to the flow through its nutrient channels and a corollary of this is that the rate of transfer of ion across the myocardial cell membrane is identical to that of the remainder of the body under all circumstances. However, it is unlikely that the $\mathrm{Na} / \mathrm{K}$ pump which controls active $\mathrm{Rb}^{+}$transport (20-23) could conform to such rigid requirements; it is difficult to believe that this mechanism would not be affected by myocardial pathology.

\footnotetext{
${ }^{1}$ Abbreviations used in this paper: $\mathrm{CBF}$, coronary blood flow; $\mathrm{CHD}$, coronary heart disease; $\mathrm{CI}$, continuous infusion; $\mathrm{CO}$, cardiac output; ${ }^{\mathrm{E}} \mathrm{O}_{2}$, myocardial oxygen extraction ratio; ${ }^{\mathrm{E}} \mathrm{Rb}$, $\mathrm{Rb}$ extraction ratio; $\mathrm{MBF}$, myocardial blood flow; $\mathrm{MVO}_{2}$, myocardial oxygen utilization; NCHD, noncoronary heart disease; TTI, tension-time index.
}

$\mathrm{Rb}$ has an advantage because it is actively taken up and retained within the cell and it is well suited for the application of the Fick principle to the measurement of flow. By this means total flow through the entire coronary circulation can be measured. No data with respect to this parameter have been published and therefore we have undertaken its measurement in a series of subjects of varied clinical composition. In this study, MBF has been simultaneously measured with $\mathrm{CBF}$ to determine their relationship.

\section{METHODS}

Patients were studied in the course of routine diagnostic cardiac catheterization and selective coronary angiography. The investigative protocol was carried out before any steps were taken in the diagnostic routine including angiography. Patients were in a fasting state and sedated approximately $1 \mathrm{~h}$ previously with diazepam intramuscularly in the dose range 5-15 $\mathrm{mg}$.

Our subjects were divided into three groups.

Coronary heart disease $(C H D)$. These patients had clinical and electrocardiographic evidence of established CHD and were functionally at least class II (NYHA). In all, subsequent angiograms revealed significant coronary arterial lesions (Table I). 16 subjects had triple artery disease, 6 double, and 4 single but not less than grade 2 . Three of the patients had associated valvular disease. There were 22 males and 4 females aged $52 \pm 8$ (mean $\pm \mathrm{SD}$ ).

Noncoronary heart disease (NCHD). Patients with congenital heart disease were specifically excluded. All individuals had clinical, electrocardiographic, and radiological evidence of established organic heart disease and functionally were at least class II (NYHA). The great majority had valvular disease and were being evaluated for possible surgical correction. In all, significant coronary disease was excluded by subsequent angiography and their diagnoses (Table I) were confirmed by subsequent hemodynamic study. The group consisted of 11 males and 8 females aged $54 \pm 10$.

A group designated as normal. These were patients with atypical chest pain in whom diagnostic study was being carried out to exclude CHD. All of these patients had normal coronary angiograms and normal hemodynamic findings on subsequent study. Five males and four females aged $40 \pm 6$ were in this group.

The principles of the ${ }^{84} \mathrm{Rb}$ coincidence counting method of Bing et al. (17), in essence an application of the hypothesis of Sapirstein (19), were employed to measure cardiac output (CO) and MBF. CBF was estimated by the Fick principle simultaneously with $\mathrm{MBF}$.

The instrumentation $(16)^{2}$ based on the concept of Bing et al. (17) represents a considerable improvement upon their original design in several respects. (a) The coincidence resolving time of $5 \times 10^{-6} \mathrm{~s}$ is 10 times shorter. This reduces the error due to background body ${ }^{84} \mathrm{Rb}$ activity to less than $2.5 \%$ under worst case conditions. (b) The detector pairs are mounted on a mobile motorized yoke permitting $360^{\circ}$ rotation in the horizontal and vertical planes as well as wide flexibility in positioning the probes relative to one another. Therefore precision in parallel alignment and centering on target organs is possible. (c) The

\footnotetext{
${ }^{2}$ Isotron. Conuclear Ltd., Ottawa, Canada.
} 
entire instrument assembly is mobile and this permits its use in the cardiac catheterization laboratory where exact placement under fluoroscopic control of both the myocardial and reference probes is effected without moving the patient. These modifications allow more effective field isolation increasing the accuracy of calibration and organ activity measurement. The first 24 patients were investigated by the single bolus method $(14,18,24)$. A catheter ${ }^{3}$ was positioned approximately $2 \mathrm{~cm}$ within the coronary sinus and another was placed in the arch of the aorta and blood sampling was commenced at the same moment from both sites at a rate of $20 \mathrm{ml} / \mathrm{min}$ and continued for precisely 2 min, by which time the myocardial isotope level had reached a plateau. ${ }^{84} \mathrm{Rb}$ in a dose of $0.25 \mu \mathrm{Ci} / \mathrm{kg}$ body weight was injected 10-15 s after the start of sampling via a catheter positioned in right ventricle or pulmonary artery. All residual activity within the entire infusion system was measured and subtracted. The arterial blood was led through a well scintillation counter set to $0.511 \mathrm{MeV}$ gamma and its activity, integrated over 1-s intervals, was recorded by means of a high-speed digital printer. This information was used to calculate $\mathrm{CO}$ by the Stewart-Hamilton principle. The precordial activity was measured by counting $0.511 \mathrm{MeV}$ gamma in coincidence mode with a $5 \times 10^{-0} \mathrm{~s}$ time window using paired 4 inch scintillation detectors positioned over the center of the heart. When cardiomegaly was present, the crystals were placed so as to include as much of the ventricular mass as possible. Lung and chest wall activity, simultaneously measured by a similar pair of detectors positioned over the right lung, was subtracted from precordial activity to obtain myocardial uptake of ${ }^{84} \mathrm{Rb}$. Counts integrated over $1-\mathrm{s}$ intervals and recorded by means of the digital printer, were monitored until myocardial activity had reached a plateau which was invariably within 2 min after injection. The myocardial uptake was read at this level since it represented the stage of complete body distribution and maximum blood clearance. The dose given was assumed to be the same as the total body uptake since $98 \%$ of $\mathrm{Rb}^{+}$is taken up by tissues (19). The contribution of the intracavitary component to the precordial activity can therefore be ignored as it is less than $2 \%$. The activity of the two blood samples was read in the well counter and the results used to calculate myocardial arteriovenous difference and hence $\mathrm{CBF}$ by the Fick principle. MBF was derived by the Bing-Sapirstein formula (17).

In the last 30 patients, $\mathrm{CBF}$ and $\mathrm{MBF}$ were measured by the continuous infusion (CI) technique. Sampling catheters were placed in the coronary sinus and aorta as for the bolus technique. In addition, a catheter was positioned in the outflow tract of the right ventricle for sampling of mixed venous blood. Iostope in a dose of $0.5 \mu \mathrm{Ci} / \mathrm{kg}$ body wt was diluted in $50 \mathrm{ml}$ of normal saline and this solution was infused by means of a Harvard pump (Harvard Apparatus Co., Inc., Millis, Mass.) into the distal pulmonary artery. The interposition of the pulmonary valve is believed to have assisted in preventing contamination of the mixed venous sample by infusate. In those cases in which transseptal catheterization had been performed, the infusion was given into the left atrium. Approximately $25 \mathrm{ml}$ was delivered over a period of $12-14 \mathrm{~min}$ and the overall infusion rate was precisely determined. The remainder of the infusate was subsequently given as part of a repeat set of determinations during cardiac pacing and these results will

${ }^{3}$ Zucker multipurpose catheter. USCI Div., C. R. Bard Inc., Glens Falls, N. Y., Cat. no. 5620. be reported separately. The mean of the differences between infusion rates during the two runs was not significantly different from $0(P>0.2)$. This degree of reproducibility implies constancy of delivery; furthermore direct testing of the system under simulated conditions showed that the infusion rate varied by less than $0.5 \%$ during a continuous $20 \mathrm{~min}$ run. At some point no earlier than 6 min after the start of infusion, by which time a steady state in blood concentration was expected, mixed venous, myocardial venous, and systemic arterial blood samples were drawn. Myocardial activity was measured, again after correction for lung and chest wall activity, and recorded as counts per minute integrated over 1 -min periods. These results were then plotted as a function of time and a linear fit obtained by the method of least squares to derive the rate of myocardial uptake. The rate of body uptake at the time of sampling was assumed to be equivalent to the rate of infusion. From these data both $\mathrm{CBF}$ and $\mathrm{CO}$ were calculated according to the Fick principle. MBF was then derived by the Bing-Sapirstein formula (17).

${ }^{84} \mathrm{Rb}$ extraction ratio $\left({ }^{\mathrm{E}} \mathrm{Rb}\right)$ is defined as $(\mathrm{A}-\mathrm{V} / \mathrm{A}) \times$ 100 , where $A$ and $V$ are respectively arterial and venous concentrations of isotope. Myocardial ${ }^{\mathbf{E}} \mathrm{Rb}$ using coronary venous concentrations and whole-body ${ }^{\mathbf{E}} \mathrm{Rb}$ using systemic mixed venous concentrations were calculated.

Separate blood samples were taken for the estimation of arterial and coronary venous lactate levels and also for arterial and coronary venous $\mathrm{O}_{2}$ content. Lactate concentration was measured by enzymatic determination (25). Blood $\mathrm{P}_{\mathrm{O}_{2}}$ measured with a Clark type electrode was converted to percent oxyhemoglobin saturation at $37^{\circ} \mathrm{C}$ (26). Hemoglobin was measured by the cyanmethemoglobin method. Whole blood $\mathrm{O}_{2}$ content was then calculated using methods described by Kelman and Nunn (27). Myocardial oxygen consumption was calculated as the product of myocardial arteriovenous oxygen content difference and CBF.

Tension-time index (TTI) was calculated as the product of heart rate and the integral of left ventricular pressure with respect to time during systole.

Total heart volume was measured according to the Jonsell formula utilizing three dimensions (long, broad, and sagittal) taken from posteroanterior and lateral chest radiographs (28).

The data on 54 patients are presented. An additional 17 patients were studied but their data are not included: in $15 \mathrm{CBF}$ was not measured because coronary sinus sampling was either not satisfactory or not done at all. In two patients in which the bolus method was used, the $\mathrm{CO}$ measurement was not deemed reliable because of the amount of distortion of the arterial indicator dilution curve due to severe valvular insufficiency. Thus, MBF could not be estimated.

\section{CALCULATIONS}

According to the Sapirstein hypothesis (19) the ratio of $\mathrm{MBF}$ to $\mathrm{CO}$ is the same as the ratio of myocardial uptake of ${ }^{84} \mathrm{Rb}$ to body uptake of the isotope (or dose injected). Thus, using the single bolus method:

$$
\mathrm{MBF}=-\frac{\mathrm{uH}(t)}{\int_{0}^{\infty} A_{1}(t) \mathrm{d} t}
$$

where $A_{1}={ }^{84} \mathrm{Rb}$ arterial concentration during first circula- 
TABLE I

List of Data in 54 Patients

\begin{tabular}{|c|c|c|c|c|c|c|c|c|c|}
\hline $\begin{array}{l}\text { Study } \\
\text { no. }\end{array}$ & Diagnosis & Technique & $\mathrm{CO}$ & MBF & $\mathrm{CBF}$ & $\begin{array}{l}\text { Myocardial } \\
\text { lactate } \\
\text { extraction }\end{array}$ & $\begin{array}{l}\text { Myocardial } \\
\text { oxygen } \\
\text { consumption }\end{array}$ & TTI & $\begin{array}{l}\text { Cardiac } \\
\text { volume }\end{array}$ \\
\hline & & & liters/min & $m l / m i n$ & $m l / m i n$ & $\%$ & $m l / m i n$ & $\underset{s / \min }{m \mathrm{Hg}}$ & $m l$ \\
\hline 13 & Normal & Bolus & 5.50 & 314 & 315 & - & 35.97 & 2,263 & 795 \\
\hline 38 & Normal & Bolus & 4.11 & 261 & 260 & 44.00 & 29.04 & 2,587 & 788 \\
\hline 53 & Normal & $\mathrm{CI}$ & 6.42 & 404 & 421 & 31.82 & 50.10 & 2,827 & 752 \\
\hline 54 & Normal & $\mathrm{CI}$ & 7.24 & 445 & 473 & 31.58 & 58.56 & 3,363 & 584 \\
\hline 61 & Normal & $\mathrm{CI}$ & 6.59 & 541 & 506 & 20.93 & 53.18 & 3,779 & 627 \\
\hline 67 & Normal & $\mathrm{CI}$ & 7.08 & 346 & 353 & - & 37.88 & 4,072 & 810 \\
\hline 69 & Normal & $\mathrm{CI}$ & 8.48 & 345 & 344 & 56.00 & 26.18 & 3,265 & 447 \\
\hline 70 & Normal & $\mathrm{CI}$ & 6.37 & 395 & 405 & 23.16 & 53.62 & 3,223 & 687 \\
\hline 71 & Normal & CI & 3.89 & 372 & 400 & 4.0 & 44.44 & 3,134 & 640 \\
\hline 11 & $\begin{array}{l}\text { Mitral regurgitation; } \\
\text { Tricuspid regurgitation; } \\
\text { Aortic regurgitation }\end{array}$ & Bolus & 6.70 & 343 & 383 & 18.57 & 32.56 & 2,741 & 1,760 \\
\hline 23 & $\begin{array}{l}\text { Aortic regurgitation; } \\
\text { Prosthetic valve }\end{array}$ & Bolus & 3.78 & 224 & 246 & 63.64 & 25.93 & 4,615 & 1,176 \\
\hline 24 & $\begin{array}{l}\text { Mitral stenosis } \\
\text { and regurgitation }\end{array}$ & Bolus & 4.98 & 407 & 382 & 26.67 & 48.06 & 3,462 & 1,176 \\
\hline 28 & Mitral regurgitation & Bolus & 4.62 & 165 & 140 & 35.71 & 14.94 & 2,815 & 981 \\
\hline 32 & $\begin{array}{l}\text { Hypertrophic obstructive } \\
\text { cardiomyopathy }\end{array}$ & Bolus & 6.56 & 188 & 328 & 25.37 & 43.10 & 2,341 & 868 \\
\hline 33 & Hypertensive heart disease & Bolus & 4.65 & 231 & 384 & 30.23 & 38.78 & 4,280 & 685 \\
\hline 34 & $\begin{array}{l}\text { Aortic stenosis } \\
\text { and regurgitation }\end{array}$ & Bolus & 5.01 & 304 & 310 & 28.30 & 28.71 & 2,979 & 970 \\
\hline 37 & Aortic regurgitation & Bolus & 4.48 & 481 & 480 & 33.33 & 39.46 & 4,466 & 1,580 \\
\hline 40 & $\begin{array}{l}\text { Aortic stenosis } \\
\text { and regurgitation }\end{array}$ & CI & 4.73 & 190 & 197 & 44.44 & 23.31 & 4,016 & 520 \\
\hline 42 & Aortic regurgitation & $\mathrm{CI}$ & 6.64 & 197 & 194 & 16.67 & 19.21 & 2,925 & 1,104 \\
\hline 43 & Aortic stenosis & $\mathrm{CI}$ & 5.55 & 138 & 140 & 30.00 & 16.10 & 3,212 & 868 \\
\hline 44 & Mitral stenosis & $\mathrm{CI}$ & 3.75 & 117 & 150 & 53.70 & 13.16 & 3,637 & 1,082 \\
\hline 45 & $\begin{array}{l}\text { Mitral stenosis; } \\
\text { Cardiomyopathy }\end{array}$ & $\mathrm{CI}$ & 5.46 & 164 & 224 & 8.75 & 21.80 & 2,423 & 1,683 \\
\hline 46 & Aortic regurgitation & $\mathrm{CI}$ & 5.20 & 255 & 278 & 21.43 & 32.19 & 2,904 & 1,094 \\
\hline 48 & Aortic regurgitation & $\mathrm{CI}$ & 4.46 & 152 & 205 & 20.00 & 19.05 & 1,795 & 898 \\
\hline 51 & Aortic regurgitation & $\mathrm{CI}$ & 5.84 & 325 & 403 & 31.25 & 35.95 & 3,610 & 1,134 \\
\hline 62 & Aortic stenosis & $\mathrm{CI}$ & 8.74 & 308 & 250 & 30.00 & 31.55 & 4,730 & 951 \\
\hline 64 & $\begin{array}{l}\text { Mitral stenosis } \\
\text { and regurgitation }\end{array}$ & $\mathrm{CI}$ & 3.42 & 280 & 327 & 6.49 & 31.75 & 3,025 & 714 \\
\hline 65 & Aortic stenosis & $\mathrm{CI}$ & 5.39 & 425 & 461 & 40.00 & 52.83 & 4,185 & 630 \\
\hline 9 & $\begin{array}{l}\text { CHD } \\
(003)\end{array}$ & Bolus & 8.11 & 433 & 475 & - & - & 2,954 & 851 \\
\hline 10 & $\begin{array}{l}\text { CHD } \\
(203)\end{array}$ & Bolus & 6.04 & 404 & 414 & - & 31.46 & 2,015 & 558 \\
\hline 12 & $\begin{array}{l}\text { CHD } \\
(333)\end{array}$ & Bolus & 4.46 & 145 & 172 & - & - & 2,755 & 1,124 \\
\hline 14 & $\begin{array}{l}\text { CHD } \\
(333)\end{array}$ & Bolus & 3.08 & 159 & 235 & - & 27.33 & 3,022 & 855 \\
\hline 15 & $\begin{array}{l}\text { CHD } \\
(131)\end{array}$ & Bolus & 3.01 & 244 & 249 & -5.56 & 34.99 & 1,529 & 996 \\
\hline
\end{tabular}


TABLE I-(Continued)

\begin{tabular}{|c|c|c|c|c|c|c|c|c|c|}
\hline $\begin{array}{l}\text { Study } \\
\text { no. }\end{array}$ & Diagnosis & Technique & $\mathrm{CO}$ & MBF & CBF & $\begin{array}{l}\text { Myocardial } \\
\text { lactate } \\
\text { extraction }\end{array}$ & $\begin{array}{l}\text { Myocardial } \\
\text { oxygen } \\
\text { consumption }\end{array}$ & TTI & $\begin{array}{l}\text { Cardiac } \\
\text { volume }\end{array}$ \\
\hline & & & lilers/min & $m l / \min$ & $m l / m i n$ & $\%$ & $m l / m i n$ & $\begin{array}{l}m m \mathrm{Hg} \\
\mathrm{s} / \min \end{array}$ & $m l$ \\
\hline 16 & $\begin{array}{l}\text { CHD } \\
(323)\end{array}$ & Bolus & 2.00 & 142 & 174 & 25.67 & 15.36 & 1,872 & 957 \\
\hline 18 & $\begin{array}{l}\text { CHD } \\
(320)\end{array}$ & Bolus & 4.20 & 319 & 346 & 0.00 & 42.77 & 2,297 & 699 \\
\hline 20 & $\begin{array}{l}\text { CHD } \\
(332)\end{array}$ & Bolus & 3.81 & 183 & 192 & 15.15 & 26.52 & 2,223 & 731 \\
\hline 21 & $\begin{array}{l}\text { CHD } \\
(233)\end{array}$ & Bolus & 3.52 & 321 & 363 & 8.33 & 40.11 & 2,503 & 649 \\
\hline 26 & $\begin{array}{l}\text { CHD } \\
(331)\end{array}$ & Bolus & 7.10 & 299 & 565 & 19.48 & 65.82 & 3,496 & 1,091 \\
\hline 27 & $\begin{array}{l}\text { CHD } \\
(002)\end{array}$ & Bolus & 4.09 & 207 & 222 & 39.81 & 18.29 & 2,779 & 693 \\
\hline 29 & $\begin{array}{l}\text { CHD } \\
(032)\end{array}$ & Bolus & 6.15 & 352 & 389 & 32.84 & 48.16 & 3,053 & 857 \\
\hline 30 & $\begin{array}{l}\text { CHD; } \\
\text { Mitral stenosis; } \\
\text { Aortic stenosis } \\
\text { (131) }\end{array}$ & Bolus & 4.25 & 214 & 229 & 40.00 & 27.73 & 2,809 & 1,580 \\
\hline 25 & $\begin{array}{l}\text { CHD; } \\
\text { Mitral regurgitation } \\
(203)\end{array}$ & Bolus & 5.33 & 155 & 181 & 17.32 & 26.25 & 2,085 & 1,115 \\
\hline 50 & $\begin{array}{l}\text { CHD } \\
(333)\end{array}$ & CI & 5.73 & 251 & 257 & 33.33 & 30.30 & $\begin{array}{c}2,967 \\
\cdot\end{array}$ & 690 \\
\hline 41 & $\begin{array}{l}\text { CHD } \\
(333)\end{array}$ & CI & 5.93 & 198 & 212 & 9.33 & 25.55 & 2,216 & 802 \\
\hline 52 & $\begin{array}{l}\text { CHD } \\
(330)\end{array}$ & $\mathrm{CI}$ & 4.26 & 248 & 257 & 0.00 & 28.01 & 4,391 & 851 \\
\hline 49 & $\begin{array}{l}\mathrm{CHD} \text {; } \\
\text { Mitral regurgitation } \\
(332)\end{array}$ & CI & 2.55 & 118 & 147 & 5.56 & 15.01 & 2,462 & 1,244 \\
\hline 55 & $\begin{array}{l}\text { CHD } \\
(313)\end{array}$ & CI & 4.64 & 149 & 155 & 27.48 & 17.42 & 3,110 & 546 \\
\hline 56 & $\begin{array}{l}\text { CHD } \\
(030)\end{array}$ & CI & 5.42 & 201 & 265 & -1.72 & 24.06 & 3,136 & 694 \\
\hline 57 & $\begin{array}{l}\text { CHD } \\
(323)\end{array}$ & CI & 7.81 & 204 & 218 & 21.26 & 21.28 & 3,552 & 951 \\
\hline 59 & $\begin{array}{l}\text { CHD } \\
(333)\end{array}$ & CI & $\begin{array}{r}9.83 \\
-\end{array}$ & 511 & 533 & 18.18 & 44.08 & 2,310 & 1,367 \\
\hline 60 & $\begin{array}{l}\text { CHD } \\
(202)\end{array}$ & $\mathrm{CI}$ & 6.01 & 182 & 213 & 33.33 & 28.54 & 4,164 & 1,011 \\
\hline 63 & $\begin{array}{l}\text { CHD } \\
(300)\end{array}$ & CI & 5.47 & 320 & 382 & 19.23 & 51.42 & 3,254 & 810 \\
\hline 66 & $\begin{array}{l}\text { CHD } \\
(233)\end{array}$ & CI & 6.10 & 414 & 480 & 0.00 & 55.82 & 2,549 & 1,155 \\
\hline 68 & $\begin{array}{l}\text { CHD } \\
(333)\end{array}$ & $\mathrm{CI}$ & 4.42 & 153 & 164 & 21.57 & 20.78 & 4,710 & 879 \\
\hline
\end{tabular}

In patients with CHD numbers in parentheses in diagnosis column indicate grade of severity of lesions in anterior descending, circumflex, and right coronary arteries in that order. $(0=$ normal; $1=<50 \%$ stenosis; $2=50-75 \%$ stenosis; $3=>75 \%$ stenosis.) 


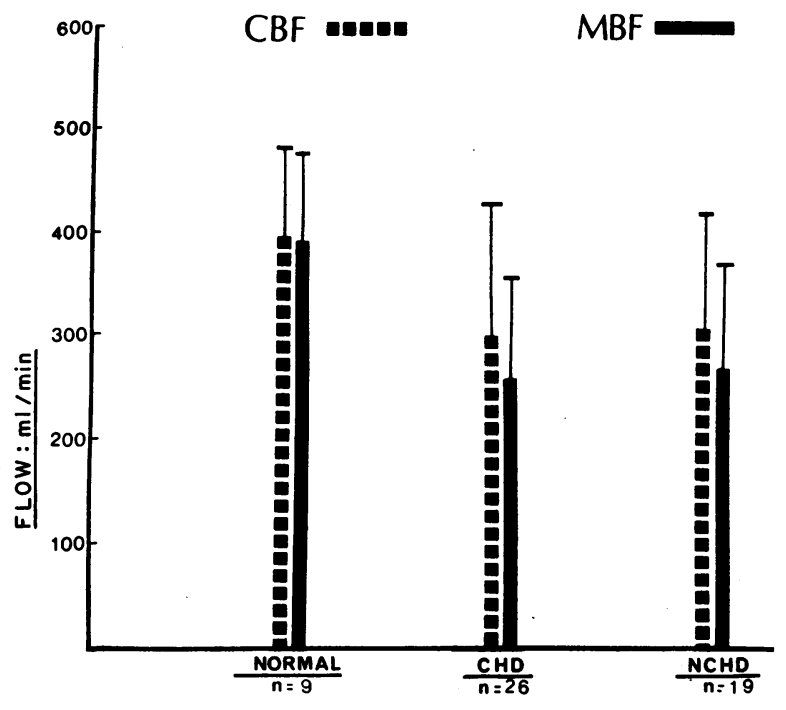

Figure 1 Summary of whole-heart perfusion data. The differences between normal on the one hand and CHD and $\mathrm{NCHD}$ on the other are significant. $\mathrm{CBF}$ and $\mathrm{MBF}$ differ significantly from one another in CHD and NCHD.

tion; $\mathrm{uH}=-$ myocardial uptake of $\mathrm{Rb}$.

$$
\mathrm{CBF}=\frac{\mathrm{uH}(t)}{\int_{0}^{t} A(t) \mathrm{d} t-\int_{0}^{t} V(t) \mathrm{d} t}
$$

where $A={ }^{84} \mathrm{Rb}$ concentration in arterial blood; $V={ }^{84} \mathrm{Rb}$ concentration in coronary sinus blood. Arterial and venous blood are collected simultaneously and continuously over a 2-min period.

When the continuous infusion method is used:

$$
\mathrm{CBF}=\frac{\mathrm{uH}(t)}{C_{a}-C_{c v}}
$$

where $\mathrm{uH}(t)$ or myocardial uptake is measured by plotting precordial counts per minute as a function of time during infusion. $C_{a}$ and $C_{c v}$ are arterial and coronary venous concentrations of isotope respectively.

$$
\mathrm{MBF}=\frac{\mathrm{uH}(t)}{C_{a}-C_{v}}
$$

where $C_{v}$ is concentration of isotope in right ventricular outflow tract.

\section{RESULTS}

Detailed findings are presented in Table I.

$C B F$. In nine normal subjects $\mathrm{CBF}$ measured 386士 $77 \mathrm{ml} / \mathrm{min}$ (mean $\pm \mathrm{SD}$ ). In 26 patients with CHD the mean value measured $288 \pm 124 \mathrm{ml} / \mathrm{min}$ and in 19 patients with $\mathrm{NCHD}$ it was $292 \pm 111 \mathrm{ml} / \mathrm{min}$. Using the $t$ test for group observations $\mathrm{CBF}$ was significantly less than normal in both CHD and NCHD $(P<0.05)$.

$M B F$. The mean values for normal, $C H D$, and NCHD were $380 \pm 81,251 \pm 105$, and $258 \pm 104 \mathrm{ml} / \mathrm{min}$, respectively. Again, the flows in both $\mathrm{CHD}$ and NCHD were significantly reduced $(P<0.01)$.

\begin{tabular}{|c|c|c|c|c|c|c|c|c|}
\hline \multicolumn{3}{|c|}{ Normal } & \multicolumn{3}{|c|}{ CHD } & \multicolumn{3}{|c|}{ NCHD } \\
\hline \multirow[t]{2}{*}{ Study no. } & $\begin{array}{c}\text { Myocardial } \\
\text { ERb }\end{array}$ & $\begin{array}{l}\text { Whole-body } \\
\text { ERb }\end{array}$ & Study no. & $\begin{array}{c}\text { Myocardial } \\
\text { ERb }\end{array}$ & $\begin{array}{c}\text { Whole-body } \\
\text { FRb }\end{array}$ & Study no. & $\begin{array}{c}\text { Myocardial } \\
\text { ERb }\end{array}$ & $\begin{array}{c}\text { Whole-body } \\
\text { ERb }\end{array}$ \\
\hline & $\%$ & $\%$ & & $\%$ & $\%$ & & $\%$ & $\%$ \\
\hline 53 & 46 & 48 & 50 & 52 & 53 & 40 & 61 & 64 \\
\hline 54 & 41 & 44 & 41 & 44 & 47 & 42 & 34 & 32 \\
\hline 61 & 37 & 34 & 52 & 60 & 62 & 43 & 60 & 60 \\
\hline 67 & 28 & 29 & 49 & 66 & 82 & 44 & 70 & 90 \\
\hline 69 & 28 & 27 & 55 & 51 & 53 & 45 & 61 & 81 \\
\hline 70 & 40 & 39 & 56 & 44 & 58 & 46 & 48 & 52 \\
\hline \multirow[t]{6}{*}{71} & 51 & 54 & 57 & 45 & 48 & 48 & 41 & 56 \\
\hline & & & 59 & 43 & 45 & 51 & 55 & 69 \\
\hline & & & 60 & 52 & 61 & 62 & 53 & 44 \\
\hline & & & 63 & 43 & 51 & 64 & 44 & 52 \\
\hline & & & 66 & 43 & 50 & 65 & 49 & 53 \\
\hline & & & 68 & 51 & 55 & & & \\
\hline Mean & $38.7 \%$ & $39.4 \%$ & Mean & $49.5 \%$ & $55.3 \%$ & Mean & $52.4 \%$ & $59.3 \%$ \\
\hline $\mathrm{SD}$ & \pm 8.8 & \pm 10.1 & & \pm 7.3 & \pm 9.8 & & \pm 10.7 & \pm 16.2 \\
\hline \multicolumn{2}{|c|}{$\begin{array}{l}\text { Significance of } \\
\text { difference } \\
\text { (paired } t \text { test) }\end{array}$} & $P>0.4$ & \multicolumn{2}{|c|}{$\begin{array}{l}\text { Significance of } \\
\text { difference } \\
\text { (paired } t \text { test) }\end{array}$} & & \multicolumn{2}{|c|}{$\begin{array}{l}\text { Significance of } \\
\text { difference } \\
\text { (paired } t \text { test) }\end{array}$} & 05 \\
\hline
\end{tabular}

TABLE II

${ }^{84} R b$ Extraction Ratio $\left({ }^{\mathrm{E}} R b\right)$ 
$C B F-M B F$. In all three groups $\mathrm{CBF}$ and $\mathrm{MBF}$ showed a good positive linear correlation. The correlation coefficients $(r)$ were respectively $0.981,0.914$, and 0.877 in normal, CHD, and NCHD groups. Values for these two parameters showed good agreement in the normal group but in CHD and NCHD, MBF was consistently lower. Thus, MBF was $98 \pm 4 \%$ of $\mathrm{CBF}$ in the normals, $88 \pm 10 \%$ in $\mathrm{CHD}$ and $90 \pm 18 \%$ in $\mathrm{NCHD}$. In comparing $\mathrm{MBF}$ with $\mathrm{CBF}$ by paired observation testing, there was no significant difference $(P>0.3)$ in the normals, whereas the differences were significant in CHD $(P<0.01)$ and NCHD $(P<0.02)$.

The situation with respect to the above flow data is summarized in Fig. 1.

Cardiac output. The mean value for normal was $6.2 \pm$ 1.5 liters $/ \mathrm{min}$, for CHD, 5.1 $1.8 \mathrm{liters} / \mathrm{min}$, and for NCHD, $5.3 \pm 1.3$ liters $/ \mathrm{min}$. The difference between normal on the one hand and CHD and NCHD on the other is of borderline significance $(0.1>P>0.05)$.

${ }^{84} \mathrm{Rb}$ Extraction ratios. The myocardial ${ }^{\mathrm{E}} \mathrm{Rb}$ was not significantly affected by the method of delivery of isotope; to whit the mean value of myocardial ${ }^{\mathrm{r}} \mathrm{Rb}$ in 23 cases in which the CI method was used was $51 \pm 9 \%$ whereas in 22 cases studied by bolus method it was $56 \pm$ $10 \%(P>0.1)$. Since the latter method was used in only two cases in the normal group, all nine normals are excluded from this comparison.

The findings detailed in Table II are confined to the $\mathrm{CI}$ studies since whole-body ${ }^{\mathrm{E}} \mathrm{Rb}$ data were available only in those cases. In the normal group the myocardial and whole-body ${ }^{\mathrm{E}} \mathrm{Rb}$ values were $39 \pm 9$ and $39 \pm 10 \%$, respectively. The corresponding values in $\mathrm{CHD}$ were $50 \pm 7$ and $55 \pm 10 \%$; and in NCHD were $52 \pm 11$ and $59 \pm 16 \%$. The myocardial : body ${ }^{\mathrm{E}} \mathrm{Rb}$ differences were significant in the latter groups $(P<0.05)$ by paired $t$ testing.

Myocardial as well as whole body ${ }^{\mathrm{E}} \mathrm{Rb}$ values were significantly lower in the normal group compared with CHD $(P<0.01)$ and NCHD $(P<0.02)$.

Myocardial oxygen utilization (Fig. 2a). Mean arterial oxygen content values in $\mathrm{ml} / 100 \mathrm{ml}$ were : normal, $17.4 \pm 3.8$; CHD, $17.8 \pm 2.5 ; \mathrm{NCHD}, 17.0 \pm 1.7$. These are normal levels.

In the normal patients mean myocardial oxygen utilization $\left(\mathrm{MVO}_{2}\right)$ was $43.2 \pm 11.5 \mathrm{ml} / \mathrm{min}$; in $\mathrm{CHD}$ it was $32.0 \pm 13.4 \mathrm{ml} / \mathrm{min}$. This difference is statistically significant $(P<0.05)$.

In NCHD the value was $29.9 \pm 11.3 \mathrm{ml} / \mathrm{min}$ which is also significantly lower than normal $(P<0.01)$.

Myocardial lactate extraction (Fig. $2 b$ ). The mean values were as follows: normal, $34.6 \pm 13.3 \%$; $\mathrm{CHD}$, $17.3 \pm 13.6 \%$; NCHD, $29.7 \pm 14.1 \%$. Whereas the normal and NCHD values were not significantly different from one another $(P>0.3)$, they were significantly higher than $\mathrm{CHD}(P<0.01)$.
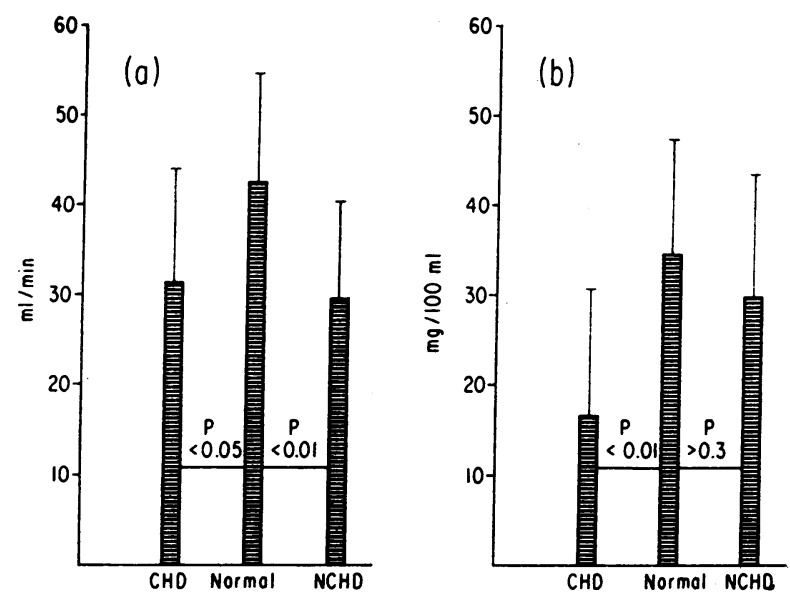

Figure 2 Both (a) $\mathrm{MVO}_{2}$ and (b) lactate extraction ratio are significantly depressed compared with normal in CHD; only $\mathrm{MVO}_{2}$ is depressed in NCHD.

Tension-time index (TTI). The following mean values were obtained. Normal, $3,168 \pm 561 \mathrm{~mm} \mathrm{Hg} \mathrm{s} / \mathrm{min}$; $\mathrm{CHD}, 2,854 \pm 765 \mathrm{~mm} \mathrm{Hg} \mathrm{s} / \mathrm{min} ; \mathrm{NCHD}, 3,377 \pm 833$ $\mathrm{mm} \mathrm{Hg} \mathrm{s} / \mathrm{min}$. The difference between the $\mathrm{CHD}$ and NCHD values were significant $(P<0.05)$ but neither was significantly different from normal $(P>0.2 ; P>$ 0.4 , respectively).

Cardiac volume. The normal mean value for cardiac volume was $681 \pm 120 \mathrm{ml}$. The mean value for CHD was $914 \pm 249 \mathrm{ml}$ which was significantly higher than normal $(P<0.02)$; and for NCHD it was $1,046 \pm 337$ $\mathrm{ml}$ which was also significantly greater than normal $(P<0.01)$.

\section{DISCUSSION}

Before a discussion of the results themselves is entered into, certain aspects of the methodology should be considered.

Two different techniques ( $\mathrm{CI}$ and single bolus) were used. The single bolus technique $(14,15,18)$ has been advocated for the measurement of whole heart $\mathrm{MBF}$ because it is relatively simple and noninvasive; most of the published human data have been obtained by this means. Since one of our goals was to compare this parameter with $\mathrm{CBF}$, we commenced the study with the bolus technique, applying it in the first 24 patients. However two disadvantages must be stated (a) The calculation of MBF depends on measurement of $\mathrm{CO}$ and when this in turn is based on the Stewart-Hamilton (indicator dilution) principle, there may be a tendency for it to be underestimated in the presence of valvular regurgitation $(29,30)$. Seven patients studied by bolus technique had some degree of valvular regurgitation (NCHD, $6 ; \mathrm{CHD}, 1)$ and it is possible that their MBF values may consequently have been artificially low. We attempted to

Total and Effective Coronary Blood Flow 369 
minimize such errors by rejecting from the series those patients ( 2 in number) found to have a marked degree of distortion of their arterial indicator curves. (b) For measurement of $\mathrm{CBF}$, blood has to be sampled from the coronary sinus at a steady rate for a period of $2 \mathrm{~min}$, as part of the procedure for determining the integrated coronary arteriovenous ${ }^{84} \mathrm{Rb}$ concentration difference. Not infrequently however, flow is not free; we were obliged to reject several patients from the series because the sampling rate was either erratic or too low.

In deference to these objections the single bolus technique was supplanted by the CI technique in the last 30 patients. Since this allowed the measurement of $\mathrm{CO}$ by the Fick method, its accuracy and therefore that of MBF was not affected by possible errors due to the presence of valvular reguritation. For the estimation of $\mathrm{CBF}$, only single samples of $5 \mathrm{ml}$ size were needed. It should be realized that relative to the bolus technique, that of $\mathrm{CI}$ is relatively invasive, even if limited to measurement of $\mathrm{MBF}$; it is more complicated and each determination takes considerably longer than the $2 \mathrm{~min}$ required for the single bolus method to allow for the collection of sufficient data from which to plot the rate of accumulation of ${ }^{84} \mathrm{Rb}$ in the myocardium. (Although we used a $12-14 \mathrm{~min}$ infusion period, 6-8 min should be sufficient).

Notwithstanding the aforementioned considerations, technique did not appear to be a factor in determining the pattern of results. In $\mathrm{CHD}$ the mean $\mathrm{CBF}$ measured by the bolus method was not significantly different from the mean $\mathrm{CBF}$ measured by the $\mathrm{CI}$ method $(P>0.5)$. The same is true for MBF $(P>0.5)$ and the CBFMBF difference $(P>0.4)$. The corresponding values in NCHD were $P>0.1, P>0.2$, and $P>0.5$. All but two of the normal cases were studied by the CI method. The similarity of the mean myocardial ${ }^{\mathrm{E}} \mathrm{Rb}$ values for the two methods ( 51 and $56 \%$ ) implies that blood sampling techniques were valid. Reassurance in this regard is especially important as far as the bolus method is conlcerned. This similarity, incidentially, is to be expected in spite of considerable contrasts between the methods in terms of magnitude and rate of change of $\mathrm{Rb}^{+}$blood levels, since an active transport mechanism is involved.

With continuous infusion blood levels of ${ }^{84} \mathrm{Rb}$ rise steeply and then reach a plateau indicating a steady state in which rate of delivery of isotope equals rate of tissue uptake (16). It may be questioned whether our blood samples were always drawn after the onset of this plateau. Assuming uniform and constant whole-body extraction, the relative blood level of a substance infused at a constant rate will be a function of the number of complete circuits through the vascular system after the start of infusion. The number of circulations required to reach a plateau will depend inversely on the extraction ratio. Thus, with an ${ }^{\mathrm{E}} \mathrm{Rb}$ of $39 \%$ (the mean value in the normals group) the blood level reaches within $1 \%$ of its plateau in 10 circulations. This is equivalent to $4.2 \mathrm{~min}$ assuming a circulation time of $25 \mathrm{~s}$. In all cases our blood sampling commenced no earlier than 6 min after the start of infusion, which appears thus to have afforded an adequate margin of safety, especially since the higher ${ }^{\mathrm{E}} \mathrm{Rb}$ in the non-normal groups would be expected to provide an even earlier plateau.

The validity of the CI technique depends upon accurate measurement of the rate of uptake of isotope by the myocardium. Some investigators have found this to be troublesome and furthermore have claimed that such uptake is not a linear function of time $(13,31,32)$. Nevertheless, we have encountered no difficulty in this regard: in the cases studied by CI technique, we obtained excellent linear correlation between myocardial ${ }^{84} \mathrm{Rb}$ uptake and time, as evidenced by an $r$ value of $0.985 \pm 0.018$ (mean $\pm \mathrm{SD} ; n=30$ ).

The linearity of infusion rate is likewise an important consideration. We believe our technique was satisfactory in this regard (see Methods).

In considering precordial detector size one can certainly question whether a diameter of 4 inches would effectively cover the range of heart sizes to be encountered and whether the myocardial uptake would not be underestimated in large hearts. Valid though we felt this point to be, we considered that the installation of larger crystals would have allowed insufficient room for the two detector pairs in most patients. In the presence of cardiomegaly we endeavored to include as much of the ventricular region as possible, sacrificing atrial and vascular areas when necessary.

$\mathrm{CBF}$ is calculated by a direct application of the Fick principle and therefore a good deal of confidence can be reposed in the measurement. An inherent assumption is that activity measured in the coronary sinus sample is equal to the mean myocardial venous activity. Since, at any given arterial blood level, the only determinant of coronary venous isotope level is myocardial ${ }^{\mathbf{E}} \mathrm{Rb}$, this assumption implies that ${ }^{\mathbf{x}} \mathrm{Rb}$ does not vary between regions of the myocardium, or that if it does, such variation is randomly distributed throughout the heart. The coronary sinus sample remains representative of any variation within its region of drainage since the effluents from the different zones are pooled in this sample and their activities automatically averaged. However, a difference between the mean ${ }^{\mathbf{E}} \mathrm{Rb}$ of the region drained by the coronary sinus and that of the rest of the myocardium would invalidate the above assumption and we cannot deny that this possibility exists. We suspect that, if present, any such difference is unlikely to be gross since $\mathrm{CBF}$ was found to have a high degree of correlation with $\mathrm{MBF}$ - a parameter whose calculation does not require the mean coronary venous isotope level.

\footnotetext{
${ }^{4}$ Peak to peak recirculation time in 33 subjects given a bolus of ${ }^{84} \mathrm{Rb} \mathrm{Cl}=24.6 \pm 3.4 \mathrm{~s}$ (mean $\pm \mathrm{SD}$ ).
} 
Systematic overestimation of CBF would result from the existence of myocardium of lower ${ }^{\mathrm{E}} \mathrm{Rb}$ confined to the coronary sinus drainage system and its degree would be no greater than the extent of the CBF-MBF difference. The difference of $10-12 \%$ occurring in this series represents the limit of our possible error from this source. It is not, however, pathognomonic of such an error.

Normal MBF values reported by other investigators using the ${ }^{84} \mathrm{Rb}$ method $(13-15,18)$ are some $35 \%$ lower than ours. We suspect a methodological basis for this difference: the increased resolution of our instrumentation as well as advantages conferred by improved mechanical design, as discussed in Methods, would be expected to yield higher net myocardial counts.

We have found $\mathrm{CBF}$ and $\mathrm{MBF}$ to be significantly below normal in the group of patients with CHD. This is in agreement with the findings of Cowan et al. (15) who measured MBF by means of ${ }^{84} \mathrm{Rb}$ coincidence counting technique. Their mean values were $74 \%$ of normal while ours are $65 \%$. While this is what might logically be expected, the majority of investigators hitherto have been unable to distinguish $\mathrm{CHD}$ from normality on the basis of resting flow values. Many used inert gas methods which are now acknowledged to overestimate flow in the presence of coronary disease $(2,4,7,33)$. More recently, however, Klocke and his collaborators ( 3 ) have used a hydrogen desaturation method in which attention is paid to the crucial importance, because of heterogeneous flow, of delivery method, sampling period, and precision of measuring technique. They found lower average flows in CHD. However, their patients were few in number and several of those "without coronary artery disease" we would have placed in the NCHD category. Cannon, Dell, and Dwyer (34) have approached the problem of nonuniform flow by using a multiple-crystal scintillation camera for external monitoring of myocardial ${ }^{133} \mathrm{Xe}$ washout. They also found average unit flows to be lower in the presence of coronary artery disease than in patients with normal coronary arteries. However, the great majority of the latter had cardiac pathology and therefore were not truly normal.

In the NCHD group we have found both $\mathrm{CBF}$ and $\mathrm{MBF}$ to be significantly less than normal. Why this should be so is a challenging puzzle. In the case of CHD, $\mathrm{MVO}_{2}$ was subnormal and this was accompanied by a significant trend toward anaerobic metabolism (Fig. 2). Since the TTI was not significantly less than normal and gross cardiac volume was significantly greater, it is likely that the demand of the myocardium for oxygen was greater than the coronary circulation could supply and hence the tendency to anaerobiasis. On the other hand in $\mathrm{NCHD}, \mathrm{MVO}_{2}$ was similarly diminished but this was not accompanied by a significant anaerobic trend. It might, therefore, appear that in $\mathrm{CHD}, \mathrm{MVO}_{2}$ was determined by perfusion whereas in NCHD perfusion was determined by $\mathrm{MVO}_{2}$. It is paradoxical that this parameter was reduced despite a significantly increased gross heart volume and a TTI that was certainly not less than normal. One may speculate that these determinants of $\mathrm{MVO}_{2}$ important though they may have been, were counterbalanced by that of myocardial contractile state, depression of which is known to occur in the presence of myocardial hypertrophy or failure $(35,36)$. Thus, it could be argued that depression of $\mathrm{CBF}$ in NCHD is the result of autoregulation.

It is necessary to acknowledge the possible role played by probe size in the genesis of our results. In a heart too large to be entirely included within the field of a 4 inch detector pair, $\mathrm{Rb}$ uptake and therefore whole-heart flow will be underestimated. The flow value obtained might actually be normal if the mass of myocardium remaining within the field were sufficient, but if pure dilatation were present, then the absolute mass of myocardium seen by the detectors and therefore the flow, might appear less than normal without there having been any change in flow per unit mass. We indeed found that total heart volumes calculated from chest radiographs were higher than normal in $\mathrm{CHD}$ and NCHD; can it be that cardiac dilatation solely explains the apparent reductions in flow in the pathological groups? We cannot refute this possibility with complete certainty but the following observations may be pertinent. We do not find that the larger the heart, the lower the flow: CBF as a linear function of total heart volume $(n=54)$ yields a correlation coefficient of only -0.04 . As our concern is only with volume increases which extend beyond the coincidence field, it is perhaps more appropriate to consider the discrepancy between the area of a 4 inch diameter circle and the frontal area of the heart, rather than total volume. CBF considered as a linear function of this area difference yields a similarly poor correlation $(r=0.016$; frontal area calculated from the long and broad axes utilized in the volume estimations (28) assuming an elliptical shape; in none of our 54 cases was frontal area less than that of a 4 inch circle).

MBF is derived on the basis of the Sapirstein hypothesis (19) according to which organ uptake of $\mathrm{Rb}$ is proportional to flow and a corollary of which is that the ${ }^{\mathrm{E}} \mathrm{Rb}$ of a given organ is equal to that of the whole body. Furthermore, MBF will be the same as $\mathrm{CBF}$ under these conditions.

In the case of our normal subjects the conditions of the Sapirstein hypothesis were met since myocardial and body ${ }^{\mathrm{x}} \mathrm{Rb}$ values (Table II) were virtually the same $(P>0.4)$. The close agreement between $\mathrm{CBF}$ and $\mathrm{MBF}$ in this group $(P>0.3)$ was simply a reflection of this fact.

In the non-normal subjects this was not the case. The mean myocardial ${ }^{\mathrm{E}} \mathrm{Rb}$ was significantly lower than

Total and Effective Coronary Blood Flow 


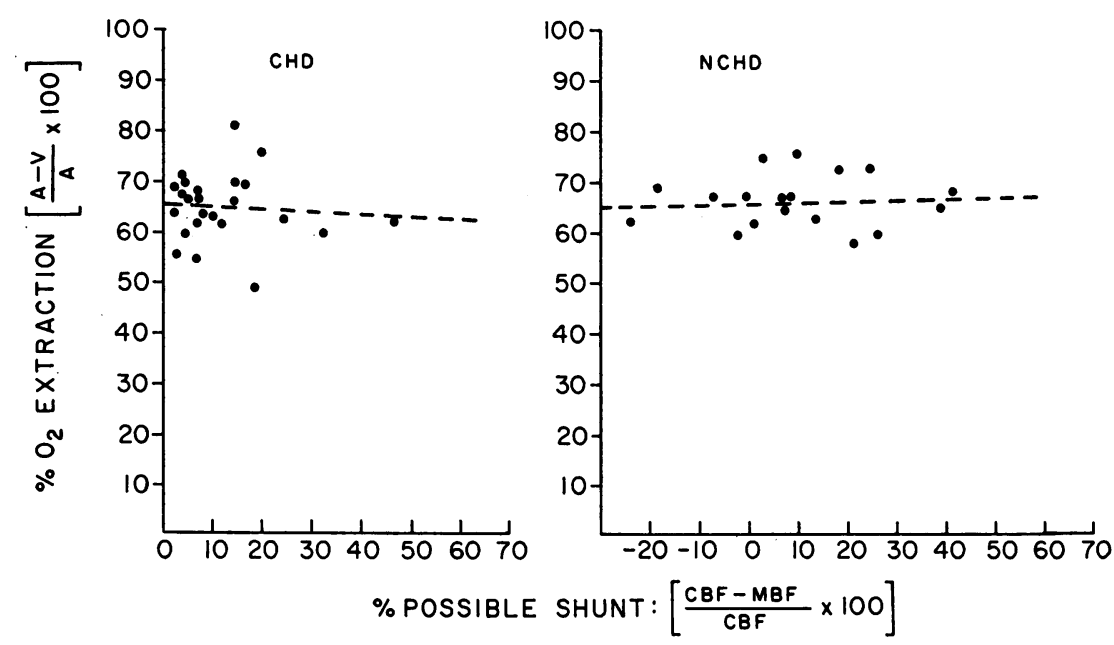

FIGURE $3{ }^{\mathrm{E}} \mathrm{O}_{2}$, a likely correlate of any shunting, vs. percent CBF-MBF difference. These plots, showing virtual absence of correlation furnish no support for the shunt hypothesis.

that of the whole-body in CHD $(P<0.01)$ and NCHD $(P<0.05)$. Accordingly, $\mathrm{MBF}$ values were significantly lower than those of $\mathrm{CBF}(P<0.01 ; P<0.02)$. These findings could have been due either to the existence of a significant nonextracting component in the coronary circulation (i.e., a shunt) or depression of the active transport of $\mathrm{Rb}^{+}$across the myocardial cell membrane.

If shunting were present one would expect to find parallel changes in measured oxygen extraction. Assuming that myocardial oxygen extraction ratio $\left({ }^{\mathrm{E}} \mathrm{O}_{2}\right)$ in extracting circuits is constant, then the greater the flow via nonextracting circuits the lower the overall ${ }^{\mathrm{E}} \mathrm{O}_{2}$ would be. This assumption is certainly true when oxygen extraction is already at its maximum as is likely to be the case when myocardial ischemia is present or when the shunt is large. In Fig. 3 myocardial ${ }^{\mathbf{E}} \mathrm{O}_{2}$ is plotted as a function of "possible shunting" expressed as percentage CBF-MBF difference. This figure shows coefficients of correlation of virtually zero in both CHD and NCHD. This tends to discount the possibility of true shunting.

The data in Table II show myocardial ${ }^{\mathrm{E}} \mathrm{Rb}$ values in the normal patients to be significantly lower than those in the $\mathrm{CHD}(P<0.01)$ and $\mathrm{NCHD}(P<0.02)$ groups. This is the converse of the findings with respect to coronary flow in these groups. This relation between flow and ${ }^{\mathrm{m}} \mathrm{Rb}$ is in accord with the observations of Moir (37). His studies on canine hearts showed coronary blood flow to be a major determinant of myocardial ${ }^{\mathbf{E}} \mathrm{Rb}$, the higher the flow, the lower the extraction.

On this basis, therefore, our ${ }^{\mathbf{E}} \mathrm{Rb}$ data, whose measurement is independent of factors such as probe size, lend credence to the lower flow values obtained in $\mathrm{CHD}$ and NCHD.

Whole-body ${ }^{\mathrm{E}} \mathrm{Rb}$ was found to be significantly lower in normal patients as compared with $\mathrm{CHD}(P<0.01)$. Conversely mean $\mathrm{CO}$ values were higher in normals compared with the other groups and the differences close to being statistically significant $(P<0.1)$. It would seem reasonable indeed to conclude that these facts are not unrelated and that Moir's conclusions with respect to the heart are equally applicable to the body as a whole.

Thus, our experience indicates that in the case of CHD and certain other forms of heart disease, particularly valvular, the total $\mathrm{CBF}$ is significantly less than normal; myocardial extraction of $\mathrm{Rb}^{+}$is significantly greater than normal, most likely as a consequence thereof.

Yet, in abnormal hearts myocardial $\mathrm{Rb}^{+}$extraction is low relative to that of the whole-body. We tend to think that this is due to depressed myocardial $\mathrm{Rb}^{+}$transport rather than true shunting. In any event nutrient or effective $\mathrm{CBF}$ consistently underestimates total $\mathrm{CBF}$ in this group.

\section{ACKNOWLEDGMENTS}

We thank Mr. Ton Frauenfelder, Mr. J. Niziol, and Mrs. C. Wozniak for their technical help and Mrs. M. Aldwinckle for work on the manuscript.

This work was supported by the Canadian and Manitoba Heart Foundations. We are indebted to Dr. J. Barwinsky for his help and for providing access to facilities made available by Medical Research Council of Canada Grant ME3271.

\section{REFERENCES}

1. Eckenhoff, J. E., J. H. Hafkenschiel, M. H. Harmel, W. T. Goodale, M. Lubin, R. J. Bing, and S. S. Kety. 1948. Measurement of coronary blood flow by nitrous oxide method. Am. J. Physiol. 152: 356.

2. Klocke, F. J., D. R. Rosing, and D. E. Pittman. 1969. Inert gas measurements of coronary blood flow. $\mathrm{Am}$. J. Cardiol. $23: 548$. 
3. Klocke, F. J., R. C. Koberstein, D. E. Pittman, I. L. Brunnel, D. G. Greene, and D. R. Rosing. 1968. Effects of heterogeneous myocardial perfusion on coronary venous $\mathrm{H}_{2}$ desaturation curves and calculations of coronary flow. J. Clin. Invest. 47: 2711.

4. Klocke, F. J., and S. M. Wittenberg. 1969. Heterogeneity of coronary blood flow in human coronary artery disease and experimental myocardial infarction. Am. J. Cardiol. 24 : 782.

5. Ross, R. S., K. Ueda, P. R. Lichtlen, and J. R. Rees. 1964. Measurement of myocardial blood flow in animals and man by selective injection of radioactive inert gas into the coronary arteries. Circ. Res. 15: 28.

6. Cohen, L. S., W. C. Elliott, and R. Gorlin. 1964. Measurement of myocardial blood flow using krypton- 85 . Am. J. Physiol. 206: 997.

7. Ross, R. S., and G. C. Friesinger. 1965. Anatomic and physiologic consideration in measurements of myocardial blood flow. Circulation. 32: 630.

8. Bassingthwaighte, J. B., T. Strandell, and D. E. Donald. 1968. Estimation of coronary blood flow by washout of diffusible indicators. Circ. Res. 23: 259.

9. Zeiler, K. L. 1965. Equations for measuring blood flow by external monitoring of radioisotope. Circ. Res. 16: 309.

10. Ganz, V., K. Tamura, J. C. Wallace, H. Marcus, and H. Swan. 1968. Measurement of great cardiac vein and coronary sinus flow in man by continuous local thermodilution. Circulation. 37 (Suppl. 6) : 80.

11. Nakamura, T., R. Katori, K. Miyazawa, K. Ishikawa, M. Yamaki, K. Tsuiki, Y. Kobayashi, A. Matsunaga, and T. Haneda. 1968. Studies on dye-dilution method (16th report): new method for measurement of coronary sinus blood flow in man. Jap. Circ. J. 32: 1845 .

12. Ganz, W., K. Tamura, H. S. Marcus, R. Donose, S. Yoshida, and H. J. C. Swan. 1971. Measurement of coronary sinus blood flow by continuous thermodilution in man. Circulation. 44: 181.

13. Cohen, A., J. P. Gallagher, E.-D. Luebs, Z. Vargo, J. Yamanaka, E. J. Zaleski, G. Bluemchen, and R. J. Bing. 1965. Quantitative determination of coronary flow with positron emitter (Rubidium-84). Circulation. 32: 636.

14. Knoebel, S. B., P. L. McHenry, L. Stein, and A. Sonel. 1967. Myocardial blood flow in man measured by coincidence counting system and a single bolus of 84-rubidium chloride. Circulation. 36: 187.

15. Cowan, C., V. Pedro, M. Duran, G. Gorsini, N. Goldschlager, and R. J. Bing. 1969. Effect of nitroglycerine on myocardial blood flow in man. Am. J. Cardiol. 24: 154.

16. Sharma, G. P. 1972. Measurement of myocardial blood flow by coincidence counting - ${ }^{84}$ rubidium technique-development, evaluation and clinical application of the technique. MSc Thesis, University of Manitoba, The National Library, Ottawa, Canada.

17. Bing, R. J., A. Bennish, G. Bluemchen, A. Cohen, J. Gallagher, and E. J. Zaleski. 1964. Determination of coronary blood flow equivalent with coincidence counting technic. Circulation. 29: 833.

18. Knoebel, S. B., P. L. McHenry, D. Roberts, and L. Stein. 1968. Myocardial blood flow in man measured by coincidence counting system and a single bolus of 84-rubidium chloride; effect of nitroglycerine. Circulation. $37: 932$.

19. Sapirstein, L. A. 1958. Regional blood flow by frac- tional distribution of indicators. Am. J. Physiol. 193: 161.

20. Kernan, R. P. 1969. Accumulation of caesium and rubidium in vivo by red and white muscles of the rat. J. Physiol. (Lond.). 204: 195.

21. Johnson, J. A. 1956. Influence of ouabain, strophanthidin and dihydrostrophanthidin on sodium and potassium transport in frog sartorii. Am. J. Physiol. 187: 328.

22. Leonard, E., and S. Hajdu. 1962. Action of electrolytes and drugs on the contractile mechanism of the cardiac muscle cell. Handb. Physiol. Sect. 2 Circulation. 1: 151.

23. Bolingbroke, V., E. J. Harris, and R. A. Sjodin. 1961. Rubidium and caesium entry, and cation interaction in frog skeletal muscle. J. Physiol. (Lond.). 157: 289.

24. McHenry, P. L., and S. B. Knoebel. 1967. Measurement of coronary blood flow by coincidence counting and a bolus of ${ }^{54} \mathrm{RbCl}$. J. Appl. Physiol. 22: 495.

25. Neville, J. F., Jr., and R. L. Gelder. 1971. Modified enzymatic methods for the determination of $\mathrm{L}-(+)$ lactic and pyruvic acids in blood. Am. J. Clin. Pathol. $55: 152$.

26. Severinghaus, J. W. 1966. Blood gas calculator. J. Appl. Physiol. 21: 1108.

27. Kelman, G. R., and J. F. Nunn. 1968. Computer Produced Physiological Tables for Calculations Involving the Relationships Between Blood Oxygen Tension and Content. Butterworth \& Co. Ltd., London.

28. Jonsell, S. 1939. A method for the determination of the heart size by teleroentgenography (a heart volume index). Acta Radiol. 20 : 325.

29. Rahimtoola, S. H., and H. J. C. Swan. 1965. Calculation of cardiac output from indicator-dilution curves in the presence of mitral regurgitation. Circulation. 31 : 711.

30. Wittenberg, S. M., F. J. Klocke, D. G. Greene, I. L. Bunnell, H. L. Falsetti, and J. A. Zizzi. 1971. Measurement of cardiac output in man with a nonrecirculating indicator. J. Clin. Invest. 50: 1466.

31. Cohen, A., E. J. Zaleski, H. Baleiron, T. B. Stock, C. Chiba, and R.'J. Bing. 1967. Measurement of coronary blood flow using ${ }^{84} \mathrm{Rb}$ and the coincidence counting method. A critical analysis. Am. J. Cardiol. 19: 556.

32. Bing, R. J., A. Rickart, and K. Hellberg. 1972. Technique to measure coronary blood flow in man. Am. J. Cardiol. $29: 75$.

33. Dwyer, E. M., Jr. 1972. Regional myocardial blood flow. Circulation. 45: 4.

34. Cannon, P. J., R. B. Dell, and E. M. Dwyer. 1972 Regional myocardial perfusion rates in patients with coronary artery disease. J. Clin. Invest. 51: 978.

35. Spann, J. F., Jr., R. A. Buccino, E. H. Sonnenblick, and E. Braunwald. 1967. Contractile state of cardiac muscle obtained from cats with experimentally produced ventricular hypertrophy and heart failure. Circ. Res. $21: 341$.

36. Chidsey, C. A., E. H. Sonnenblick, A. G. Morrow, and E. Braunwald. 1966. Norepinephrine stores and contractile force of papillary muscle from failing human heart. Circulation. 33: 43.

37. Moir, T. W. 1966. Measurement of coronary blood flow in dogs with normal and abnormal myocardial oxygenation and function. Comparison of flow measured by a rotameter and by $\mathrm{Rb}^{\text {s6 }}$ clearance. Circ. Res. 19: 695.

Total and Effective Coronary Blood Flow 